\title{
Identification of an equilibrium component in the mantle sources of carbonatites using high precision $\mathrm{Ca}$ stable isotopes
}

\author{
ELSA AMSELLEM ${ }^{1}$, MARTIN SCHILLER ${ }^{2}$, MARTIN
} KLAUSEN $^{3}$, AMAURY BOUYON ${ }^{4}$, VIRGINIA ROJAS ${ }^{5}$ AND MARTIN BIZZARRO ${ }^{6}$

${ }^{1}$ Starplan, Globe Institute, University of Copenhagen

${ }^{2}$ University of Copenhagen

${ }^{3}$ Stellenbosch University

${ }^{4}$ Institut de Physique du Globe de Paris/CNRS UMR 7154-

University of Maryland

${ }^{5}$ Institut de Physique du Globe de Paris

${ }^{6}$ Centre for Star and Planet Formation, Globe Institute, University of Copenhagen

Presenting Author: elsa.amsellem@sund.ku.dk

Carbonatites are rare carbonate-rich igneous rocks whose origin is still highly debated. Their genesis and chemical evolution is complex and it is still not clear which process accounts for their carbonate-rich composition. Calcium stable isotopes have the potential to inform the reaction kinetics underlying the isotope fractionation recorded in natural samples ([1], [2]) and, thus, may help to shed light on carbonatite genesis. Here, we apply the new ${ }^{42} \mathrm{Ca}-{ }^{44} \mathrm{Ca}-{ }^{48} \mathrm{Ca}$ triple-isotope approach and report high-precision $\mathrm{Ca}$ stable isotope data for 91 carbonatites and associated silicate rocks from different localities and ages raging from 3000 to $67 \mathrm{Ma}$. These data are corroborated by ${ }^{87} \mathrm{Sr} /{ }^{86} \mathrm{Sr}$ data for 64 carbonatites and associated silicate rocks as well as $\mathrm{C}$ and $\mathrm{O}$ isotopic data for 56 carbonatites. These data reveal a wide range of stable $\mathrm{Ca}$ isotope compositions from $\mathrm{d}^{44 / 42} \mathrm{Ca}_{\text {SRM915b }}=-0.26 \pm 0.01 \%$ to $0.36 \pm 0.01 \%$. The lightest samples also record positive residual anomalies in the kinetically mass fractionated data. This observation establishes that a component of the $\mathrm{Ca}$ present in these samples has been fractionated by mass dependent equilibrium processes. Equilibrium isotope fractionation is expected to dominate at low temperature and, moreover, marine carbonates can be enriched in the lightest $\mathrm{Ca}$ isotopes relative to BSE (e.g., [3]). As such, the presence of an equilibrium fractionation component in carbonatites provides strong evidence for recycled $\mathrm{Ca}$ from the Earth's surface in the mantle source of $\mathrm{Ca}$ - and $\mathrm{Mg}$-rich carbonatites and their associated alkali silicate rocks.

[1] M. Schiller, C. Paton, and M. Bizzarro, "Calcium isotope measurement by combined HR-MC-ICPMS and TIMS," J. Anal. At. Spectrom., vol. 27, no. 1, pp. 38-49, 2012, doi: 10.1039/c1ja10272a.

[2] M. A. Antonelli et al., "Kinetic and equilibrium $\mathrm{Ca}$ isotope effects in high-T rocks and minerals," Earth Planet. Sci. Lett., vol. 517, pp. 71-82, 2019, doi: 10.1016/j.epsl.2019.04.013.

[3] M. S. Fantle and E. T. Tipper, "Calcium isotopes in the global biogeochemical Ca cycle: Implications for development of a Ca isotope proxy," Earth-Science Rev., vol. 129, pp. 148-177, 2014, doi: 10.1016/j.earscirev.2013.10.004. 